\title{
The Game Playing and Development Trend of Cross-boundary Vocal Performance Phenomenon and Traditional Vocal Music
}

\author{
Cheng guo
}

Sichuan University of Culture and Arts, Sichuan, Mianyang, 621000

Keywords: vocal music cross-border phenomenon; game; development

\begin{abstract}
Many splendid civilizations have been born in China's long history of development. Chinese traditional vocal music culture is one of them. Based on the long-term and complex historical development of the Chinese nation and a wide variety of national cultures, traditional vocal music has been continuously developed and achieved remarkable achievements in the 5,000-year period. This paper expounds the history of the evolution of traditional Chinese vocal music, analyzes the significance of today's cross-border vocal performances, and presents personal insights based on the future trends of traditional Chinese vocal music.
\end{abstract}

\section{Introduction}

Generally speaking, most of the traditional vocal music known to people is single, while the singing works reflect the characteristics of easy to understand. However, due to the change of The Times, the traditional vocal performance continues to infiltrate the cultural, political, economic and other fields. This phenomenon has given new blood and development opportunities to traditional vocal music, which has enabled the development of traditional vocal music from the former unity to the diversified development, fully meeting people's requirements for the traditional vocal music form, and taking a broader road.

\section{The history of the development of vocal music in China}

The development of vocal music in China originated from the ancient time. It arose in the process of picking, hunting and other labors in the Stone Age. In the unique environment, some syllables were repeated and formed into the earliest folk songs. After Qin unified China, although the Yuefu organization was formed in the court, the singing art did not develop and even stagnate. After the Han Dynasty, the Qin Dynasty was preserved and many folk songs circulating in the folks were collected. Rap music was born in the Han and Wei Dynasties. In the Sui and Tang Dynasties, there appeared a more comprehensive and perfect type of drama. After the Song and Yuan Dynasties, it formed an art song that was not difficult to sing and difficult. The Yuan "Miscellaneous" and the "Song Qu" of the Golden Age formed a Yuanqu together. Most of the folk songs that appeared in the Ming and Qing Dynasties were inspired by folklore and the love story of the workers. After the start of the Opium War, the content of folk songs changed significantly, and the words of the original songs were re-written into "new folk songs." After the founding of New China, a large number of national vocal singers appeared in China, which improved the science and perfection of folk singing. Today, there is a phenomenon of local cross-border singing, enriching the connotation of vocal music and promoting the further development of traditional vocal music.

\section{The significance of vocal music cross-border phenomenon}

\subsection{Cross-border singing phenomenon satisfies the law of development}

Analyze the objective law and essence of the development of things from the perspective of development, that is, the objective things are the process of continuous development and change. Things are driven by the main factors, and their movements are gradually advanced through the past, present and future. In the same way, cross-border singing is not only a continuation of the 
traditional form of vocal music, but also the premise and basis for the establishment of new forms of vocal music in the future. It is a familiar vocal type environment, in the process of gradual improvement and development, and constantly adapting to different types of vocal music, The product that was born and worn. In-depth study of cross-border singing phenomenon, not only to understand its past, analyze its current situation, but also to judge its future development trend. The essence of cross-border singing is the blending of different singing methods, the self-improvement and progressive development of singing, and the objective and objective law that can satisfy the development of things.

\subsection{Cross-border singing reflects change, tolerance and innovation}

The characteristics of the artistic era are characterized by innovation, change and tolerance. The form of vocal cross-border singing itself reflects both tolerance, change and innovation, as well as its real value. The core of vocal cross-border is "innovation" and "combination”, which is mainly reflected in the cross-border singing, the constant self-regulation of various singing methods, making up for their own defects, learning other singing advantages, fostering strengths and avoiding weaknesses, integrating with each other, and constantly establishing cross-border The way the performance is performed. At the same time, song creators and performers who sang across the border constantly improve and update their own experiences, and constantly increase their understanding of music. This process is a process of re-innovation and re-processing of art. This music innovation and self-transcendence, through the cross-border singing form to enhance the connotation and expressiveness of the song, highlights the incomparable artistic spirit.

\subsection{Cross-border singing to meet the needs of commercialization of the market}

At present, the types of social music are more prosperous and diversified. People no longer satisfy a single type of music, and need a variety of singing methods. There is a big contradiction between the audience's constantly improving auditory needs and backwardness and single vocal forms. At this time, the birth of diversified music types provides people with more conditions and opportunities to choose music types. Therefore, cross-border singing can satisfy people's requirements for music types, which leads to cross-border singing becoming a common phenomenon. Diversified music types have also shown great business opportunities while being liked by people. Cross-border singing is not only the embodiment of musicians exploring new integrating point and exceeding themselves, but also the effective mode and carrier of commercial operation. With the help of business operation mode, the depth and scope of the influence of new vocal forms can also be expanded and more economic benefits can be obtained based on its artistic charm. It is worth noting that cross-border singing should uphold professional ethics and artistic ethics and made it its mission to enhance the people's ability to appreciate music and aesthetic tastes, instead of paying attention to economic benefits and ignoring artistic value.

\section{The game playing and development trend of traditional vocal music}

\subsection{Respect different vocal cultures and realize self-cultural identity to develop traditional vocal music.}

In the development process of Chinese traditional vocal music, the perfection and unity of vocal music culture should be achieved in the rich and colorful vocal music culture, which is based on the multidialectical unity formed on the premise of respect, rather than the unity forced by the overbearing power. China's diversified vocal music cultural accumulation should pay attention to the views of harmony in diversity and seeking common ground while reserving differences, so that traditional vocal music can gain an open platform and realize diversified development. It will show its own accumulation on the open platform, revealing a gorgeous, unique and totally different charm. Only in this way can we promote the healthy and sustainable development of Chinese traditional vocal music. In order to protect the uniqueness and nationality of Chinese traditional vocal music to the greatest extent, and to better integrate with global mainstream vocal music, traditional vocal 
music must strive from different aspects in order to win and develop in the international vocal music game. It is necessary to fully understand that the inheritance and development of traditional vocal characteristics is a prerequisite for China to realize the diversification and specialization of vocal music culture.

China has a civilization history of 5,000 years, and there's vocal culture in every stage. While the vocal civilization itself has achieved remarkable achievements, it is also a part of the Chinese outstanding civilization. In the rich and brilliant vocal music culture in Chinese history, there are a large variety of popular vocal music cultures, which involve more than 400 kinds of art forms. Singing skills and performance methods varies for different vocal forms. In this respect, "Chinese traditional vocal singing" reflects both uniqueness and creativity. In the current vocal culture environment, all the content of such "creative and unique" culture is the premise and foundation of the diversification of Chinese traditional vocal music. It is necessary to fully grasp the advantages, realize the cultural identity, and then obtain better development while respecting the vocal culture.

\subsection{Traditional vocal music should use modern technology to cope with the development and changes of the times}

Under different historical backgrounds, people's lifestyle, living conditions and differences in social and economic systems will cause obvious distinctions in people's ideological connotation, aesthetic taste, and culture at that time, and then their demand for vocal music changes. This overall framework is constantly developing and there will be no static situation. It is required that vocal music performance should combine with the differences of the times to gradually change itself, and merge with the vocal needs, the modern aesthetics and culture.

The creative traditional vocal music innovation should be reflected with multiple forms and pluralism on the premise of the existing vocal music culture. Vocal cross-border singing is a positive attempt and innovation. In this way, vocal singing can reflect the contemporaneity and promote the healthy and sustainable development of Chinese traditional vocal music.

Professor Jin Tielin uniformly calls popular singing, bel canto, primitive singing and national singing the scientific singing style. These singing methods are constantly mentioned in various fields related to music in China, which means that the way that singer fully expresses the style and work content through his singing skills is scientific singing. In terms of angle, the relationship between different singing styles is not non-interfering and completely parallel, and different singing methods are related to each other and exist independently by some commonality. Therefore, as far as vocal music singing is concerned, we can explore the commonalities between different singing styles, make them related to each other, and learn the special parts of various singing styles to perfect and complement each other and achieve cross-border singing. Vocal singers should sing traditional vocal works of different languages, different regions and different styles, use a variety of singing methods to better improve and interpret works and constantly improve their overall quality and singing level. Only in this way can we promote the development of traditional vocal music and make it more dazzling.

\section{Conclusion}

The crossover of vocal music is the need for the development of vocal music performance and is the product of the progress of the times. Cross-border vocal performance is a novel form of expression, effectively transforming a single, traditional form of singing and promoting the sustained and healthy development of vocal music art. At present, China's economic and social development is stable, and people's quality of life is constantly improved. People need diversified and multi-level vocal performances, and there will be more crossover phenomenon of vocal music singing. In this process, we must learn from the advantages of traditional vocal music, and integrate into the essence of other music to promote the sustained development of traditional vocal music. 


\section{References}

[1] Ji Yu. On the cross-border phenomenon of vocal music singing[J]. Art Evaluation, 2018(01): 53-54 +57.

[2] Fu Yun. Multiple Integration and Development of Vocal Music Cross-border Singing[J]. Journal of Anhui University of Technology (Social Science Edition), 2017, 34(03): 46-47 +50.

[3] Fanyifu. wubixia and Andelie- boqieli's vocal music "cross-border" phenomenon inspired vocal music education[J]. Voice of the Yellow River, 2016(17): 10-11.

[4] Wang Zhen. On the problem of cross-border singing in vocal music art[J]. Theatre House, 2016(23): 60.

[5] Shen Depeng. The fusion of cross-border singing and modern national vocal music education[J]. Yuefu Xinsheng (Journal of Shenyang Conservatory of Music), 2016, 34(01): 188-190. 